\title{
VISIBILIDADE DO PROJ ETO DE EXTENSÃO PARA PROMOÇÃO DA ASSISTÊNCIA PERIOPERATÓRIA: PONTO DE VISTA MULTIDISCIPLINAR
}

\author{
Visibility of the Extension Project for Promotion of \\ the Perioperatory Attendance: Multidisciplinary's Vision \\ Visibilidad del Proyecto de Extensión para Promoción \\ de la Atención Perioperatoria: Visión Multidisciplinaria
}

Norma Valéria Dantas de Oliveira Souza ${ }^{1}$

Luciana Ranauro Assumpção ${ }^{4}$

\author{
Maristela Freitas Silva ${ }^{2}$ \\ Fabiana Maia Morgado 5
}

Keila Sullen de Moura Nunes ${ }^{3}$ Luanna Klarem de Azevedo Amorin ${ }^{6}$

\section{Resumo}

Pesquisa qualitativa, cujo objeto foi a visibilidade do projeto de extensão "Orientando o Cliente em Situação Cirúrgica para Diferenciar o Cuidado" junto aos profissionais que compõem a equipe multidisciplinar de saúde. Objetivos: identificar o conhecimento da equipe multidisciplinar acerca das atividades desenvolvidas no projeto de extensão e analisar a relevância conferida pela equipe multidisciplinar acerca das atividades do projeto para a qualidade da assistência. Cenário: duas enfermarias cirúrgicas de um hospital universitário do Rio de Janeiro. As informações foram coletadas através de entrevista com 16 sujeitos. Após aplicar a análise de conteúdo, os resultados foram: a enfermagem e o serviço social conheciam as atividades do projeto, ao passo que médicos e nutricionistas desconheciam. Os sujeitos que conheciam o projeto conferiam-lhe relevância, pois propiciava bem-estar à clientela. Conclusão: o projeto tem visibilidade junto à equipe de enfermagem e serviço social, porém necessita traçar estratégias para alcançar visibilidade com médicos e nutricionistas.

Palavras-chave: Enfermagem. Cirurgia. Relações Comunidade-Instituição.

\begin{abstract}
Qualitative research, the purpose of the study was the visibility of the extension project "Guiding the client in surgical situation to care differentiate" within professionals that compose the health multidisciplinary team. Objectives: To identify the knowledge of multidisciplinary heath workers team regarding the activities developed at extension project and to analyze the importance given from multidisciplinary team about the project activities to assistance quality. Scenario: Two surgical nursing rooms at a university hospital at Rio de Janeiro. It has been collected data from 16 people through interview. After applying content analysis the results were: nursing and social service professionals were aware of the project activities, but doctors and the nutritionist were not. The individuals that were aware of the project have given it great importance, because it would cause welfare state to the clients. Conclusion: It can be concluded that the project has visibility within nursing and social service teams, but it is necessary to trace strategies in order to reach visibility within doctors and nutritionists.
\end{abstract}

Keywords:

Nursing. Surgery. Community-Institutional Relations.

\section{Resumen}

Investigación cualitativa, cuyo objeto fue la visibilidad del proyecto de extensión "Guiando el cliente en situación quirúrgica para diferenciar el cuidado" junto a los profesionales que integran el equipo multidisciplinario de salud. Objetivos: identificar el conocimiento del equipo multidisciplinario sobre las actividades desarolladas en el proyecto de extensión y analisar la importancia conferida por el equipo multidisciplinario sobre las actividades del proyecto para la calidad de la asistencia. Escenário: dos enfermerías quirúrgicas de un hospital universitario de Río de Janeiro. Fueron recopilados datos a través de una entrevista con 16 sujetos. Después de usar el analisis de contenido los resultados fueron: los profesionales del ofício de enfermera y servicio social conocian las actividades del proyecto, pero los medicos y los nutricionistas no lo conocian. Los sujetos que conocian el proyecto lo conferiran importancia, pues causava bien-estar a los clientes. Conclusión: el proyecto tiene visibilidad junto al equipo del ofício de enfermera y servicio social, pero es necesario planificar estrategias para alcanzar visibilidad con medicos y nutricionistas.

Palabras clave:

Enfermería. Cirugía. Relaciones Comunidad-Institución. 


\section{INTRODUÇÃO}

0 objeto desse estudo foi a visibilidade do projeto de extensão intitulado "Orientando o Cliente em Situação Cirúrgica para Diferenciar o Cuidado" junto aos profissionais que compõem a equipe multidisciplinar das clínicas de cirurgia geral de um hospital universitário. 0 desejo de investigar esse objeto surgiu a partir de inquietaç̃̃es sobre qual era o conhecimento da equipe multidisciplinar que atuava no contexto da cirurgia geral sobre as atividades desenvolvidas pelos membros do referido projeto e a importância conferida a essas atividades para a qualidade da assistência prestada a clientela em situação cirúrgica.

0 referido projeto foi implementado em março do ano de 2005 e tem como lócus de atuação as enfermarias de cirurgias gerais do Hospital Universitário Pedro Ernesto (HUPE), da Universidade do Estado do Rio de Janeiro (UERJ). Seus objetivos são: ajudar o cliente a compreender a dinâmica do processo de internação pelo qual está passando, desmitificar a experiência cirúrgica e contribuir para a redução das alterações biopsíquicas e sociais decorrentes do procedimento cirúrgico. Os membros do projeto têm como atividade principal o fornecimento de orientações que auxiliem a clientela a compreender melhor a experiência cirúrgica, aproximando-a dessa vivência.

As estratégias de fornecimento das orientações se dão de duas formas: reuniões semanais com grupos de clientes que se encontram no período pré-operatório e orientações individuais voltadas para os clientes que se encontram em alta hospitalar, os quais necessitam de esclarecimentos para 0 autocuidado no domicílio.

As reuniões semanais têm duração de 60 minutos e buscam fornecer orientações sobre o período perioperatório intrahospitalar. Realiza-se, no primeiro momento da reunião, 0 levantamento das necessidades de orientação da clientela, e, posteriormente, executam-se atividades que visem atender as necessidades de esclarecimento, dúvidas e inquietações a respeito da experiência cirúrgica. Tal atividade consiste em fazer uma explanação problematizada, utilizando álbum seriado com gravuras referentes às situações do período perioperatório e fotos do ambiente do Centro Cirúrgico. Esses recursos instrucionais viabilizam uma maior aproximação com o contexto desconhecido do perioperatório. Os clientes que participam das reuniões são aqueles que, após serem convidados e esclarecidos acerca dos objetivos do projeto, manifestam o desejo e a disponibilidade física e emocional para integrarem as reuniões do grupo de orientação.

A outra atividade do projeto caracteriza-se no fornecimento de orientações individuais voltadas para o cuidado no domićlio, posterior à decisão de alta hospitalar pela equipe multidisciplinar. Esta atividade objetiva capacitar clientes e familiares para o autocuidado, assim como minimizar reações emocionais desagradáveis decorrentes da alta hospitalar. Para tanto, utilizam-se folhetos explicativos que abordam pontos fundamentais para o autocuidado, como: cuidado com a incisão cirúrgica e o curativo, a alimentação, o retorno à atividade sexual e à atividade produtiva, atenção às funções vesicointestinais e orientações acerca de possíveis complicações cirúrgicas inerentes à intervenção sofrida, além das manifestações clínicas próprias de quem se submeteu a um procedimento cirúrgico.

Ressalta-se que o conceito de autocuidado utilizado pelos membros do projeto fundamenta-se nos preceitos de Dorothea E. Orem, que o entende como "a prática de atividades, iniciadas e executadas pelos indivíduos, em seu próprio benefício para manutenção da vida, da saúde e do bem-estar" 1:91. A autora complementa, enfatizando que as capacidades dos indivíduos para autocuidar estão relacionadas com a idade, o estado de desenvolvimento, a experiência de vida, orientação sócio-cultural, saúde e recursos disponíveis. Assim sendo, dependendo dessas variáveis, familiares e amigos podem ser envolvidos no processo de autocuidado, caso a pessoa esteja temporária ou permanentemente limitada para o desenvolvimento do autocuidado.

0 desejo de executar este projeto fundamentou-se na vivência das professoras que atuam nas enfermarias cirúrgicas supervisionando os internos da Faculdade de Enfermagem da UER, assim como no conhecimento científico envolvendo o significado da experiência cirúrgica e suas repercussões biopsicossociais.

Submeter-se a uma cirurgia pode resultar em sentimentos desagradáveis como temor, frustração e ansiedade, pois está ancorada no senso comum uma simbologia negativa relacionada a esta situação. Inquietações e medos povoam o universo de sentimentos das pessoas que irão vivenciar um procedimento cirúrgico, ligados a: reações anestésicas, alteração da autoimagem, medo do diagnóstico, afastamento social, risco de complicações cirúrgicas imediatas e tardias². Independente da extensão cirúrgica e da gravidade da doença que leva à cirurgia, existe um percentual significativo de repercussões nas dimensões física, social e psíquica dos clientes, podendo, inclusive, interferir no transoperatório e no resultado da cirurgia, caso os potenciais de risco não sejam considerados durante 0 período perioperatório ${ }^{3}$.

Além disso, a vivência cirúrgica é algo nebuloso e freqüentemente representa um universo desconhecido para a população em geral. Considerando que o desconhecido provoca medo, ansiedade, angústia e, muitas vezes, bloqueios para a ação e a transformação de situações críticas passíveis de serem modificadas, verificou-se que, ao se fornecerem orientações para o cliente em período perioperatório, possibilita-se uma visão mais aproximada da experiência cirúrgica, auxiliando no enfrentamento do estresse cirúrgico e no processo de autocuidado ${ }^{3}$. Através das orientações, também é possível desmitificar questões relacionadas à cirurgia e suas conseqüências biológicas, psicológicas e sociais, minimizando temores e ansiedades, além de fornecer alternativas para que ele tenha uma participação ativa/interativa no cuidado de sua própria saúde 4 .

Uma maneira eficaz de realizar orientações para a saúde pode ser através da formação de grupos que contam com pessoas de interesses comuns ou que se encontram em situações semelhantes. Esses grupos configuram-se numa estratégia que possibilita a interação de pessoas em situações similares, estimula cada indivíduo a assumir responsabilidades na manutenção de sua saúde, conferindo-lhes subsídios para a compreensão das suas possibilidades e limites para 0 
autocuidado, além de fornecer conhecimentos para o enfrentamento das situações de saúde-doença ${ }^{5}$.

Por outro lado, a pessoa que se submete a uma cirurgia e recebe alta hospitalar depara-se, por exemplo, com: incisões cirúrgicas, ostomias, drenos, cateteres, além de outras situações que geram questionamentos e dúvidas. Assim, percebe-se que surgem sentimentos desagradáveis como medo e ansiedade relacionados ao autocuidado no domicílio. Ressalta-se ainda que a convalescença do cliente que se submeteu a uma cirurgia se dá, em grande parte, no domicílio, e, por isso, a pessoa e familiares que vivenciaram a experiência cirúrgica devem estar preparados para cuidar-se e detectar alterações relativas ao procedimento?.

A partir da complexidade que envolve o cliente em situação cirúrgica, decidiu-se então, implementar o projeto de extensão explicitado anteriormente, o qual encontra-se em execução há dois anos e um mês. Após esses anos de atuação, surgiu 0 desejo de investigar a visibilidade do projeto junto à equipe multidisciplinar das clínicas de cirurgia geral.

A fim de guiar o processo investigativo traçaram-se as seguintes questões nor teadoras: qual é o conhecimento da equipe multidisciplinar que atua nas enfermarias de cirurgia geral sobre as atividades do projeto de extensão "Orientando o Cliente em Situação Cirúrgica para Diferenciar o Cuidado"?; e qual a importância conferida pela equipe multidisciplinar às atividades do projeto para qualidade da assistência prestada nas enfermarias cirúrgicas?

Selecionaram-se dois objetivos para a pesquisa: identificar o conhecimento da equipe multidisciplinar acerca das atividades desenvolvidas pelos membros do projeto de extensão "Orientando o Cliente em Situação Cirúrgica para Diferenciar o Cuidado" e analisar a relevância conferida pela equipe multidisciplinar às atividades desenvolvidas pelos membros do projeto para qualidade da assistência prestada aos clientes em situação cirúrgica.

\section{METODOLOGIA}

0 estudo foi qualitativo, descritivo e tipo estudo de caso. 0 cenário para o desenvolvimento da pesquisa foi o Hospital Universitário Pedro Ernesto, situado no Município do Rio de Janeiro, onde se executa em média cinqüenta cirurgias diariamente, nas mais diversas especialidades médicas, atendendo a clientela em todas as faixas etárias.

Os sujeitos do estudo foram 16 profissionais: quatro enfermeiras, oito auxiliares de enfermagem, dois médicos, uma assistente social e uma nutricionista. Excluíram-se fisioterapeuta e psicólogo devido à pouca inserção desses profissionais em termos de horas trabalhadas nas enfermarias de cirurgia geral e à rotatividade elevada dos mesmos nas unidades de internação. Adotaram-se como critério de seleção dos sujeitos a disponibilidade e o desejo dos profissionais em quererem participar da pesquisa.

Após contato inicial com os sujeitos, explanação dos objetivos da pesquisa e assinatura do Termo de Consentimento Livre e Esclarecido, realizou-se a coleta dos dados através da técnica de entrevista semi-estrutura, as quais foram gravadas em aparelho de MP3 com autorização prévia dos sujeitos. Esta etapa da pesquisa ocorreu nos meses de novembro a dezembro de 2006 e nos meses de fevereiro e março de 2007.

Destaca-se que foram seguidas as determinações da Resolução 196/96 do Conselho Nacional de Saúde/ MS, que regulamenta as pesquisa com seres humanos. Assim, a pesquisa foi apreciada pelo Comitê de Ética em Pesquisa (CEP) do Hospital Universitário Pedro Ernesto em junho de 2005, obtendo parecer positivo, liberando o desenvolvimento da pesquisa.

As informações coletadas foram analisadas e interpretadas à luz da análise temática de conteúdo. Segundo Bardin ${ }^{6}$, esse método presta-se à compreensão do sentido da comunicação, mas também desvia o olhar analiticamente para uma outra significação, uma outra mensagem entrevista através ou ao lado da mensagem primeira, que pode ser de natureza psicológica, sociológica, política ou histórica.

Assim, após a transcrição e leitura das entrevistas, com a identificação dos significados, procedeu-se à codificação das unidades de registro visando identificar e problematizar as temáticas contidas nos registros para a construção do arcabouço lógico do pensamento do sujeito. A aplicabilidade desse método propiciou uma análise ampla e profunda do material coletado, resultando na construção de três categorias: o conhecimento da equipe multidisciplinar acerca do projeto de extensão; a importância do projeto para qualidade da assistência; e estratégias para aumentar a visibilidade do projeto.

Para manter o anonimato, preservando a privacidade dos sujeitos da pesquisa, utilizou-se uma codificação, objetivando impedir qualquer tipo de ligação entre o conteúdo das entrevistas e os sujeitos. Assim, à medida que eram transcritas as entrevistas, elas recebiam o código $E 1$, E2 e assim sucessivamente, obedecendo a uma ordem cronológica de realização das transcrições.

\section{ANÁLISE DOS DADOS}

$1^{\text {a }}$ Categoria - 0 conhecimento da equipe multidisciplinar acerca do projeto de extensão.

Constatou-se que os profissionais de enfermagem e a assistente social conhecem as atividades desenvolvidas pelos membros do projeto de extensão. Através das falas selecionadas a seguir é possível evidenciar essa análise.

Conheço [...] a forma educativa que vocês trabalham, que facilita ao paciente entender o que vai acontecer com ele. Vocês trazem os folders e cartazes, eu acho isso muito interessante, especial mesmo. E9

[...] sei, e como às vezes não dá tempo de a gente conversar com o paciente com calma sobre o procedimento que vai acontecer, vocês auxiliam muito nesta parte, já que nós sabemos que eles estão recebendo as orientações, e aí a gente fica mais tranqüilo. A gente acaba trabalhando um complementando o outro [...]. E4

A constatação de que profissionais de enfermagem e do serviço social conhecem as atividades do projeto de extensão caracterizou-se num dado positivo, com base nas inferências de Meirelles e Erdmann ${ }^{7}$, os quais asseveram que as 
intervenções de saúde incluem campos de ação variados com o enfoque de melhorar a saúde e reorientar os serviços de assistência, além de fazer com que as pessoas sejam protagonistas da sua própria saúde, o que exige uma atuação conjunta e não puramente técnica da equipe de saúde. Verificase então, que a atuação dos membros do projeto favorece 0 trabalho articulado, conjunto e de complementaridade com a equipe, uma vez que as atividades de extensão são conhecidas, esperadas nos dias determinados para sua atuação e valorizadas pelos profissionais que trabalham nas enfermarias de cirurgia geral. Além disso, constata-se que o projeto apresenta certa visibilidade no contexto da cirurgia geral, pois os profissionais de enfermagem e do serviço social entrevistados relataram conhecê-lo.

Através da segunda fala destacada anteriormente também é possível analisar que a atuação dos membros do projeto gera uma relação interpessoal positiva, de confiança e de respeito, pois a ação de orientar é "delegada" aos membros do projeto, mas essa delegação é feita de forma positiva, pois existe confiabilidade no trabalho desenvolvido pelos membros do projeto.

De todas as atividades desenvolvidas no projeto, as que foram mais citadas pelos sujeitos que conheciam o projeto foram as orientações desenvolvidas no período pré-operatório (orientações em grupo). A fala apresentada a seguir revela o que foi analisado.

Não sei de todas as atividades, mas gosto daquela que vocês levam os pacientes para varanda, acho que eles falam mais, botam seus sentimentos pra fora [...], se sentem bem por estarem tendo atenção de vocês. E2

Quando se questionaram os profissionais da equipe de medicina e de nutrição se eles conheciam as atividades do projeto de extensão, o resultado foi o desconhecimento. Destacaram-se as falas a seguir a fim de caracterizar essa análise.

Alguns pacientes me falam que já sabem como vai ser a cirurgia, mas sinceramente nunca perguntei sobre isso, nunca tive curiosidade. E10

Não, não conheço. Assim, com a falta de tempo, a gente só conversa sobre os problemas da enfermaria, o que está faltando, o que vai ser feito e sai todo mundo correndo para resolver outras coisas. Acaba que a gente nem sabia o que vocês fazem com um projeto desses na enfermaria, que é até interessante, porque o paciente chega no centro cirúrgico, e eu já peguei paciente lá de calcinha, porque não tirou, não quis tirar e ninguém pediu pra ficar sem. E16

A primeira pergunta da entrevista caracterizava-se no seguinte questionamento: você conhece o projeto de extensão que é desenvolvido nesta enfermaria, o qual tem como objetivo orientar clientes acerca da situação cirúrgica? Diante da resposta do desconhecimento, partia-se para esclarecer os sujeitos do estudo sobre as atividades desenvolvidas no projeto. Após esse esclarecimento, os profissionais de medicina e de nutrição consideravam-no interessante e útil.

No entanto, diante desse desconhecimento, considera-se que a visibilidade do projeto junto à equipe multidisciplinar ainda não é satisfatória, necessitando-se traçar estratégias para alcançar a visibilidade homogênea junto aos vários profissionais que compõem a equipe multidisciplinar, inclusive, facilitando a construção de parcerias para que as orientações possam abranger as várias áreas da saúde que estão envolvidas com a assistência perioperatória.

$2^{\mathrm{a}}$ Categoria - A importância do projeto para qualidade da assistência.

A análise do conteúdo das entrevistas revelou que as atividades desenvolvidas pelos membros do projeto foram consideradas relevantes para o bem-estar do cliente em situação cirúrgica, pois, segundo os sujeitos, os clientes ao receberem as orientações passam a ter conhecimento sobre suas patologias, os cuidados que deveriam ter nos períodos pré e pós-operatório, assim como no domicílio, resultando na diminuição da ansiedade e expectativa relacionada à cirurgia. Através das falas destacadas é possível verificar esta afirmação.

[...] ai a gente vê que eles realmente ficam mais seguros e confiantes em ir para a cirurgia, isso até deve diminuir a pressão deles, porque eles ficam tão mais calmos. E5

[...] o dientejávem com uma expectativa, eacho que eleverbalizar nos grupos os seus sentimentos diminui a ansiedade. E7

Zago ${ }^{8}$ comenta que a educação para saúde, a orientação para o autocuidado, desenvolve no cliente a independência parcial da equipe de saúde e possibilita a redução da ansiedade pós-cirúrgica, repercutindo, inclusive, no tempo de internação e na recuperação pré e pós-alta. Sendo assim, a orientação de perioperatório é vista pela autora como de grande importância para elevar o padrão da assistência, visto que os clientes passam a entender o porquê de alguns cuidados, como: a manutenção do jejum; retirada de próteses, adereços e roupas íntimas; a necessidade da deambulação precoce e as alterações orgânicas esperadas no período pós-operatório. A partir desse conhecimento, os clientes tendem a participar ativamente do seu processo saúde-doença e trabalhar em conjunto com a equipe de saúde para sua rápida recuperação, favorecendo uma melhor adaptação à sua nova condição de vida.

Outra atividade desenvolvida pelos membros do projeto e que alcançou visibilidade junto à equipe de enfermagem foram as orientações voltadas para o cuidado domiciliar. A equipe conferiu revelância a esta atividade uma vez que a clientela obtém alta hospitalar e invariavelmente adquire uma incisão cirúrgica, entre outras situações com que ela muitas vezes não tem o devido preparo psicocognitivo para lidar. Além disso, considerando que 0 cliente quando internado tem suas necessidades atendidas pela equipe de enfermagem, se sentido amparado, quando ocorre a alta, ele precisa se autocuidar. Esta situação pode causar impacto negativo na pessoa; dessa forma, a atividade de orientação ao cliente para o cuidado no domicílio foi valorizada e incentivada nos discursos dos sujeitos da pesquisa.

Acho importante esse contato individual porque, no momento da alta, a maioria dos pacientes está acompanhada e a orientação não fica só com ele, vocês acabam orientando também o familiar, que muitas vezes é quem vai cuidar deste paciente em casa. Isso minimiza muito as possíveis complicações. E9 
0 projeto, na visão dos sujeitos do estudo, contribui para qualidade da assistência, destacando-se as repercussões positivas que ele possibilita no processo saúde-doença dos clientes em situação cirúrgica e para os familiares, que vivenciam essa situação a reboque. Sobre esta situação, Tavares $^{9}$ traz uma importante contribuição quando diz que situações que propiciam a aprendizagem e a capacitação devem ser compreendidas como sendo um processo de revitalização e superação de modo individual e coletivo, objetivando a qualificação, reafirmação ou reformulação de valores, conduzindo a relações integradoras entre os sujeitos envolvidos numa determinada práxis. Através da análise da fala destacada a seguir, foi possível constatar esta possibilidade de transformação dos agentes presentes neste contexto.

Eu acho importante porque os pacientes aprendem, os acompanhantes aprendem, os alunos aprendem e até eu procuro ficar atenta ao que vocês dizem para me atualizar. E8

$3^{\text {a }}$ Categoria - Estratégias para aumentar a visibilidade do projeto.

Aos sujeitos que não conheciam o projeto foi feito o seguinte questionamento: que estratégias você considera importantes para que os profissionais conheçam o projeto? Esse questionamento visava reunir dados para que os membros do projeto de extensão pudessem traçar estratégias a fim de alcançar a visibilidade satisfatória entre os vários profissionais que compõem a equipe multidisciplinar de saúde. As respostas fornecidas possibilitam repensar alguns pontos na dinâmica de funcionamento do projeto, como também na dinâmica do trabalho das enfermarias de cirurgia geral. Destacaram-se falas que caracterizam essa análise:

Eu acho que a gente fica tão ocupada com outras coisas que não sabe o que acontece. Aqui a gente faz um monte de coisa, somos sozinhos, e tem 10,15 pacientes pra ver, mais ambulatório, mais centro cirúrgico, mais pendências da enfermaria, e tudo isso faz com que a gente acabe não sabendo o que acontece. E16

Então eu acho que falta comunicação e falta interesse também da nossa parte, de ficar mais atento, de reparar mais, até mesmo pela rotina que é muito corrida. E10

\section{Referências}

1. Foster PC, Janssens NP. Dorothea E. Orem. In: George JB, organizadora. Teorias de enfermagem. Porto Alegre (RS): Artes Médicas; 1993.

2. Meeker MH, Rothrock JC. Cuidados de enfermagem ao paciente cirúrgico. 10ª ed. Rio de Janeiro (RJ): Guanabara Koogan; 1997.

3. Souza NVO, Silva MF, Marquês GS, Rodrigues FR, Cruz EJER. Avaliando as orientações de enfermagem no período perioperatório segundo perspectivas do cliente cirúrgico. Rev OBJN. 2006 [citado 23 jan 2007] 5(1): 01-10. Disponível em: www.uff.br/nepaeobjnurse.htm

4. Santos SSC, Luis MAV. A relação da enfermeira com o paciente cirúrgico. Goiânia (GO): AB; 1999.

5. Friedlander ED, Lage AC. Acompanhamento do paciente pos cirurgico por meio da visita domiciliar. Acta Paul Enferm 2003 jan/mar; 16(1): 49-55.
Constata-se que o ritmo laboral intenso, com volume elevado de atividades, acaba tornando o profissional cansado, desinteressado e alienando diante de uma organização e um processo de trabalho hospitalar pouco racional, que imobiliza e desmotiva os profissionais ${ }^{10}$. Essas questões acabam por inviabilizar a comunicação, as trocas de experiência e as socializações dos interesses e sucessos.

\section{CONCLUSÃO}

Considera-se que o projeto de extensão ainda não atingiu a visibilidade esperada, uma vez que nem todos os profissionais que compõem a equipe multidisciplinar de saúde das enfermarias de cirurgia geral o conhecem. A equipe médica e de nutrição o desconheciam por razões diversas, como: o ritmo intenso de trabalho com volume elevado de atividades, a falta de comunicação eficaz, o pouco interesse em conhecer mais profundamente o trabalho de outras equipes.

Além disso, apreendeu-se que os membros do projeto poderiam ter envidado maiores esforços para difundir e socializar as atividades por eles desenvolvidas, até como estratégia para buscar parceiras ao fornecimento de orientações muldisciplinares, almejando atender as necessidades dos clientes de forma integral. No entanto, acredita-se que um primeiro passo foi dado para minimizar esse desconhecimento quando se questionaram os profissionais sobre ele e se tornou oportuno explicar sobre sua operacionalização.

Porém essa estratégia ainda é pouca, e nessa tentativa de cooptar mais profissionais para atuar no projeto e socializar as ações desenvolvidas pelos seus membros, têm-se convidado os profissionais para participar das orientações, e vem-se observando uma participação ativa da assistente social, uma tímida participação das nutricionistas e nenhuma participação da equipe médica. Ou seja, o movimento para transformação desse quadro já foi desencadeado, necessita-se agora de mantêlo, assim como adicionar outras estratégias que venham possibilitar a atuação muldisciplinar no projeto.

Quanto aos profissionais que conheceram o projeto, verificouse um posicionamento de valorizar sua importância, pois entendem que ele é um veículo para elevar a qualidade da assistência, estimulando sua permanência nas clínicas de cirurgia geral e sugerindo ampliá-lo para as clínicas cirúrgicas especializadas.

6. Bardin L. Análise de Conteúdo. Lisboa (P0): Ed 70; 1995.

7.MeirellesBHS. ErdmannAL.Ainterdisciplinaridade como construção do conheaimento em saúde e enfermagem. Texto \&Contexto Enferm 2005 jul/set; 14(3).

8. Zago MMF. Considerações sobre o ensino do paciente cirúrgico. Rev Esc Enferm USP 1993 abr; 27(1) p. 67-71

9.Tavares CMM. A educação permanente da equipe de enfermagem para o cuidado nos serviços de saúde mental. Texto \& Contexto Enferm 2006 abr/jun; 15(2): 287-95

10. Machado JMH, Correa MV Conceitos de vida no trabalho na análise das relações entre processo de trabalho e saúde no hospital. Inf Epidemiol SUS 2002; 11(3): 159-66.

Recebido em 30/05/2007 Reapresentado em 22/10/2007 Aprovado em 05/11/2007 